Z. Phys. Chem. 219 (2005) 439-454

(C) by Oldenbourg Wissenschaftsverlag, München

\title{
Characteristic Lattice Complexes
}

\author{
By J. Hauck and K. Mika* \\ Institut für Festkörperforschung, Forschungszentrum Jülich, D-52425 Jülich, Germany
}

(Received October 13, 2004; accepted December 16, 2004)

\section{Surface Structures / Phyllotaxis / Alloys / Organic Structures}

2D and 3D lattice complexes with increased self-coordination numbers $T_{i}, i=1-3$, of nearest, second and third neighbors were derived for characteristic Wyckoff sets with zero or one parameters. Structure types of adsorbed atoms in 2D or elements A in 3D and $\mathrm{A}_{x} \mathrm{~B}_{y}$ compounds are approximated to the list of lattice complexes. Covalent bonding or electronic effects of atoms like lone electron pairs or Jahn-Teller distortion give rise to deviations from lattice complexes. Homogeneous structures $\mathrm{A}_{x} \mathrm{~B}_{y}$ with identical A-A or B-B self-coordination numbers $T_{1}, T_{2}, T_{3}$ of nearest, next-nearest and third neighbors are selected for different systems like magnetic ordering with $\mathrm{A}=\oplus$ and $\mathrm{B}=\ominus$ spin direction or crystals of organic molecules with different orientations.

\section{Introduction}

Some basic phenomena can be interpreted from different viewpoints. A very well-known example of the atomistic world is the simultaneous particle or wave-like character. The wave-length $\lambda$ and mass $m$ are related by the de Broglie relation $(\lambda=h / m v)$. Other examples of different viewpoints can be found for atoms in solid matter [1]. The atoms in solid matter are characterized by rigid spheres in crystallography or as point masses interconnected by spring forces in IR spectroscopy or the Ising model [2,3]. The crystallographic atoms are on different positions $a, b, c$ of a space group with certain symmetry elements and parameters $x y z$. Deviations from this position are given by thermal parameters or additional contributions on electron density maps. The present article will show, that the different positions $a, b, c$ of space groups can be approximated by characteristic lattice complexes with maximum selfcoordination numbers. In the next section simple examples for educational purposes are considered for ladies $\mathrm{A}$ and gentlemen $\mathrm{B}$ sitting in $1 \mathrm{D}$ rows in school or an opera house. 1D ordering of elements A and B in the space groups with and without inversion center is not observed. Adsorbed atoms A on metal

\footnotetext{
* Corresponding author. E-mail: k.mika@fz-juelich.de
} 
surfaces and different inorganic structures $\mathrm{A}_{x} \mathrm{~B}_{y}$ will follow as examples for $2 \mathrm{D}$ and $3 \mathrm{D}$ structures. The self-coordination numbers of $\mathrm{A}$ and $\mathrm{B}$ can frequently be correlated with attractive or repulsive interactions of the Ising model $[2,4]$. Small numbers of nearest neighbors $T_{1}$ indicate repulsive $\mathrm{A}-\mathrm{A}$ interactions, small numbers $T_{2}$ of next-nearest neighbors attractive interactions, as will be outlined for $1 \mathrm{D}$ ordering in the next section. The maximum Madelung factor $\mathrm{MF}=2 \ln 2$ at repulsive $\mathrm{A}-\mathrm{A}$ interactions is obtained for $\mathrm{B}$ positions between two A positions.

\section{1D lattice complexes}

The ordering of a single species $\mathrm{A}$ with different sizes like $\mathrm{A}=\mathrm{Cu}$ atoms, macromolecules, colloidal particles, leaves or ladies can be characterized by the A-A self-coordination numbers $T_{i}, i=1-3$, of nearest, next-nearest and third neighbors [2]. The ladies in a moslem school for example have $T_{1}=2$, $T_{2}=2$ and $T_{3}=2$ neighbors at distances $d=1,2$ and 3 between the chairs. A minimum of $n=7$ ladies in a row is required for the 222 value of the center lady. The different $T_{i}$ values of ladies close to the aisle are added to the averaged $T_{i}$ values $2(n-1) / n, 2(n-2) / n, 2(n-3) / n$ for $n$ ladies in a row. The 222 ordering of ladies is a homogeneous 1D structure. A second homogeneous 1D structure is found for a school desk with two ladies and a vacant place $\square$ to the next desk. The A positions in the periodic sequence (within the commas) ,AA $\square$,AA $\square$, etc. have $T_{1}=T_{2}=1$ and $T_{3}=2$ A neighbors at distances 1, 2 and 3. The 222 and 112 orderings are 1D lattice complexes, which are obtained in the same way as 2D or 3D lattice complexes [5]. The Wyckoff positions (1a) $x=0$, (1b) $x=1 / 2$ and (2c) $x, \bar{x}$ can be occupied by $\mathrm{A}$ in a periodic $1 \mathrm{D}$ ordering with lattice constant $a=1$ and inversion center. The self-coordination numbers $T_{i}=2, i=1-3$, are obtained for (1a) or (1b) with distances $d=1,2$ and 3 between A positions. The $x$ values of the (2c) position can vary within the asymmetric range $0<x \leq 1 / 4$. The $T_{i}$ values are 222 for $x=1 / 4$ and 112 for all other $x$ values. The distances between nearest neighbors $2 x$ and second neighbors $1-2 x$ are identical at $x=1 / 4$. The same lattice complexes with distances $1-2 x, 2 x$ or $a$ between nearest, second or third neighbors, respectively, are obtained for $x$ values in the range $1 / 4<x<1 / 2$. Structures with self-coordination numbers 112 (distorted structure) can be approximated to the increased 222 values by variation of $x$ to $x=1 / 4$. The vacancies $\square$ between A positions are diminished. The 1D ordering without inversion center contains only the lattice complex with $T_{i}$ values 222 . The lattice complex of a second species $\mathrm{B}$ is translated by $x$. The maximum Madelung factor $\mathrm{MF}=2 \ln 2$ for $\mathrm{A}=\oplus$ and $\mathrm{B}=\ominus$ is obtained from

$$
\begin{array}{r}
\operatorname{MF}(x)=-x[\Psi(x)+\Psi(1-x)-2 \Psi(1)], 0 \leq x \leq 1 / 2, \Psi(x)=\Gamma^{\prime}(x) / \Gamma(x), \\
\Psi(1 / 2)=-\gamma-2 \ln 2, \Psi(1)=-\gamma \quad(\gamma=\text { Euler constant })
\end{array}
$$


for $x=1 / 2(\mathrm{MF}(0)=1)$. The B positions are on the border of the A-A Dirichlet domain as will be outlined for $2 \mathrm{D} \mathrm{AB}$ structures in Sect. 3. The A and B atoms form a chain with $T_{i}=2, i=1-3 \mathrm{~A}$ or $\mathrm{B}$ atoms. The distances between A, B and $\square$ in the 112 complex are identical for $x=1 / 6$.

The homogeneous structures $\mathrm{A}_{x} \mathrm{~B}_{y}$ of two species like $\mathrm{A}=$ ladies and $\mathrm{B}=$ gentlemen can be derived for the two 1D lattice complexes with $\mathrm{A}-\mathrm{A}$ selfcoordination numbers of the minority component $\mathrm{A}$ and the ratio $y / x \geq 1$ : $\mathrm{AB}$,

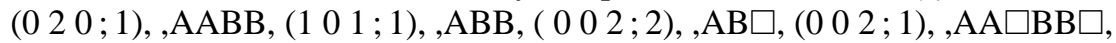
$(100 ; 1)$ and ,AB $\square \mathrm{BA} \square,(010 ; 1)$. Homogeneous structures with periodic borders in $1 \mathrm{D}$ are obtained for $\mathrm{A}$ and $\mathrm{B}$ on a round table like $n=4$ people in the sequence $\mathrm{AABB}(101 ; 1)$ or $\mathrm{ABAB}(020 ; 1)$ and $T_{i+n}=T_{i}$ values. The $T_{i}$ values of all 1D structures can be plotted in two structure maps [2]. The homogeneous structures are on the corners of a $T_{1} T_{2} T_{3}$ polyhedron. The corner structures with minimum or maximum $T_{2}$ values like $101 ; 1$ or $020 ; 1$ are obtained at attractive or repulsive $\mathrm{A}-\mathrm{A}$ interactions [2]. The number of lattice complexes with different $T_{i}, i=1-3$ values is increased in 2D or 3D to more than 23 or 250 , as will be outlined in the present investigation for invariant or univariant solutions with some examples for homogeneous structures of elements $\mathrm{A}$ and compounds $\mathrm{A}_{x} \mathrm{~B}_{y}$. Homogeneous $2 \mathrm{D}$ or $3 \mathrm{D}$ structures can frequently be characterized by the $1 \mathrm{D}$ sequences of $\mathrm{A}$ and $\mathrm{B}$ atoms like $\mathrm{AB}, \mathrm{AB}$ or $\mathrm{AABB}$ in [100], [110] or [111] direction.

\section{2D lattice complexes with increased self-coordination numbers}

Periodic 2D structures are usually characterized by the lattice constants $a$ and $b$, the angle $\gamma$ between $a$ and $b$ and the positional parameters $x$ and $y$. Homogeneous structures of a single species A are obtained for the occupation of a single Wyckoff position. Positions with identical neighborhood like the positions of a square net with $T_{1}=T_{2}=T_{3}=4$ neighbors at distances $1, \sqrt{2}$ and 2 can be described by the Wyckoff position 11-a or b (Table 1). The number of different values in a Wyckoff position is restricted to asymmetric ranges of $b / a$ or $x$ values in characteristic lattice complexes $[5,6]$. The increased $T_{i}$ values are obtained for certain ratios $b / a$ of lattice constants, angles $\gamma$ between $a$ and $b$ or positional parameters $x$ and $y$. The $T_{1}, T_{2}$ or $T_{3}$ values at intermediate values are decreased. The self-coordination numbers 444 of the square net with $\gamma=90^{\circ}$ between $a$ and $b$ axes for example vary to 422 for $60^{\circ}<\gamma<90^{\circ}$ and reach 666 at $\gamma=60^{\circ}$ (hexagonal net) in the characteristic Wyckoff position 2-a-d (Table 14.1 of Fischer and Koch [5]). The values vary further to $244, \underline{246}$, $242, \underline{264}, 224, \underline{26}$ and 222 . The $\cos \gamma$ values for increased $T_{i}$ values (underlined values) are given in Table 1. Identical structures are obtained at $90^{\circ} \pm \gamma$. The 222 values at low $\gamma$ values (or $\gamma$ values close to $180^{\circ}$ ) correspond to the linear chain. The formation of $1 \mathrm{D}$ chains from $2 \mathrm{D}$ structures is also observed for the characteristic Wyckoff set 6-a-d with $\gamma=90^{\circ}$ and small ratios 
Table 1. Self-coordination values $T_{1}, T_{2}, T_{3}$ for 2D lattice complexes of characteristic Wyckoff positions [5] with less than two parameters $b / a, \cos \gamma$ or $x$. The $\cos \gamma$ value of 2-a-d position is varied for the special case $a=b$. Maximum Madelung factors MF of $\mathrm{A}^{+} \mathrm{B}^{-}$with translation between $\mathrm{A}$ and $\mathrm{B}$ positions.

\begin{tabular}{|c|c|c|c|c|c|c|c|}
\hline $\begin{array}{c}\cos \gamma \\
b / a=1\end{array}$ & $T_{i}$ & MF & Tr. (B) & $x$ & $T_{i}$ & MF & Tr. (B) \\
\hline & & & & & & 2-c & \\
\hline & & -a-d & & $(3-\sqrt{7}) / 4$ & 146 & 1.3095 & $1 / 21 / 2$ \\
\hline$>17 / 18$ & 222 & & & $(-1+\sqrt{3}) / 4$ & 521 & 1.4014 & $1-4 \times 0$ \\
\hline $17 / 18$ & 226 (a) & 1.3863 & $1 / 21 / 2$ & $1 / 4$ & 444 & 1.6155 & $1 / 41 / 4$ \\
\hline $7 / 8$ & 264 & 1.3863 & $1 / 21 / 2$ & & & & \\
\hline $3 / 4$ & 246 & 1.3871 & $1 / 21 / 2$ & \multicolumn{4}{|c|}{ 14-d } \\
\hline $3 / 4$ & 246 & 1.3871 & $1 / 20$ & $1 / 6$ & 446 & 1.2852 & $1 / 32 / 3$ \\
\hline $1 / 2$ & 666 & 1.5422 & $1 / 31 / 3$ & & & & \\
\hline 0 & 444 & 1.6155 & $1 / 21 / 2$ & \multicolumn{4}{|c|}{$15-c$} \\
\hline$b / a$ & $T_{i}$ & MF & Tr. (B) & $\begin{array}{c}1 / 3 \\
(3-\sqrt{3}) / 3 \\
1 / 2\end{array}$ & $\begin{array}{l}666 \\
428 \\
446\end{array}$ & $\begin{array}{l}1.5422 \\
1.3199 \\
1.2852\end{array}$ & $\begin{array}{l}1 / 31 / 3 \\
3 x-13 x-1 \\
1 / 32 / 3\end{array}$ \\
\hline \multicolumn{4}{|c|}{ 6-a-d } & \multicolumn{4}{|c|}{17 -a } \\
\hline$<1 / 3$ & 222 & & & - & 666 & 1.5422 & $1 / 32 / 3$ \\
\hline $1 / 3$ & 224 (a) & 1.3863 & $01 / 2$ & \multicolumn{4}{|c|}{ 17-b } \\
\hline $\begin{array}{l}1 / 2 \\
1 / \sqrt{3}\end{array}$ & $\begin{array}{l}244 \\
226 \text { (b) }\end{array}$ & $\begin{array}{l}1.3863 \\
1.4044\end{array}$ & $\begin{array}{l}01 / 2 \\
1 / 21 / 2\end{array}$ & - & 363 & $\begin{array}{l}-\mathbf{D} \\
1.3249\end{array}$ & $1 / 31 / 3$ \\
\hline 1 & 444 & 1.6155 & $1 / 21 / 2$ & \multicolumn{4}{|c|}{$17-c$} \\
\hline$x$ & $T_{i}$ & MF & Tr. (B) & \multicolumn{4}{|c|}{ 17-d } \\
\hline \multicolumn{4}{|c|}{ 11-a,b } & $1 / 4$ & 222 & 1.1863 & $1 / 121 / 6$ \\
\hline - & 444 & 1.6155 & $1 / 21 / 2$ & $\begin{array}{c}2-\sqrt{3} \\
1 / 3\end{array}$ & $\begin{array}{lll}2 & 3 & 1 \\
3 & 6 & 3\end{array}$ & $\begin{array}{l}1.2045 \\
1.3249\end{array}$ & $\begin{array}{l}x / 32 x / 3 \\
1 / 92 / 9\end{array}$ \\
\hline \multicolumn{4}{|c|}{ 11-d,e } & \multicolumn{4}{|c|}{ 17-e } \\
\hline $1 / 4$ & 224 (b) & 1.2990 & $1 / 40$ & $(-3+2 \sqrt{3}) / 3$ & 223 & 1.2038 & $x 0$ \\
\hline$(2-\sqrt{2}) / 2$ & 314 & 1.2632 & $2 x-1 / 21 / 2-x$ & $\begin{array}{c}(-3+2 \sqrt{3}) / 3 \\
1 / 6\end{array}$ & $\begin{array}{l}2 \\
243\end{array}$ & 1.2301 & $1 / 60$ \\
\hline$(-1+\sqrt{3}) / 2$ & 125 & 1.2727 & $1 / 21 / 2$ & $(3-\sqrt{3}) / 6$ & 422 & 1.3271 & $1-4 x x$ \\
\hline \multicolumn{4}{|c|}{ 11-f } & $(3-\sqrt{3}) / 3$ & 344 & 1.1892 & $5 x-27 x-3$ \\
\hline$(-1+\sqrt{2}) / 2$ & 232 & 1.3717 & & & & & \\
\hline $1 / 4$ & 444 & 1.6155 & $1 / 41 / 4$ & & & & \\
\hline
\end{tabular}

$b / a($ or $a / b)$. (The Wyckoff set 9-a,b with $b / a=\tan \gamma / 2$ is identical with 2-a-d, $a=b, \cos \gamma$.) The other lattice complexes of Table 1 with the variation of the positional parameter $x$ show a different degeneracy. The multiplicity of atoms is decreased at small or large $x$ values. The four positions with the special $x$ and $y$ coordinates $x 0, \bar{x} 0,0 x$ and $0 \bar{x}$ of characteristic Wyckoff position 11-d,e for example decrease to one or two positions at $x=0$ or $1 / 2$, respectively. Some lattice complexes like the square net $(444)$ or the hexagonal net $(666)$ occur in several characteristic Wyckoff positions with one variable parameter (Table 1). 
Table 2. Self-coordination values $T_{1}, T_{2}, T_{3}$ of nearest, next-nearest and third A-A neighbors of adsorbed atoms A in different structure types [7] with A on top (T), bridge (B) or hollow $(\mathrm{H})$ positions. The $T_{i}$ values in brackets are approximate.

\begin{tabular}{|c|c|c|c|}
\hline$T_{1} T_{2} T_{3}$ & substrate & structure type & adsorbate \\
\hline \multirow{7}{*}{666} & $\mathrm{Al} \quad$ (111) & $(1 \times 1)$ & $\mathrm{O}$ on $\mathrm{T}$ \\
\hline & $\mathrm{Cu}$ (111) & $(1 \times 1)$ & $\mathrm{Ni}$ on $\mathrm{H}$ \\
\hline & $\mathrm{Ni}(111)$ & $(\sqrt{3} \times \sqrt{3}) \mathrm{R} 30^{\circ}$ & $\mathrm{CO}$ on $\mathrm{B}$ \\
\hline & Ir $\quad(111)$ & $(\sqrt{3} \times \sqrt{3}) \mathrm{R} 30^{\circ}$ & $\mathrm{S}$ on $\mathrm{H}$ \\
\hline & $\mathrm{Rh}$ (111) & $(\sqrt{3} \times \sqrt{3}) \mathrm{R} 30^{\circ}$ & $\mathrm{CO}$ on $\mathrm{T}$ \\
\hline & $\mathrm{Ni} \quad(111)$ & $(2 \times 2)$ & $\mathrm{S}$ on $\mathrm{H}$ \\
\hline & $\mathrm{Cu}$ & $(2 \times 2)$ & Cs on $\mathrm{T}$ \\
\hline \multirow[t]{5}{*}{$\left(\begin{array}{lll}6 & 6 & 6\end{array}\right)$} & Rh (111) & $(2 \times 2)$ & $3 \mathrm{CO}$ on $\mathrm{T}$ or $\mathrm{B}$ \\
\hline & $\mathrm{Pd} \quad(100)$ & $(2 \sqrt{2} \times \sqrt{2}) \mathrm{R} 45^{\circ}$ & $2 \mathrm{CO}$ on $\mathrm{B}$ \\
\hline & $\mathrm{Rh}$ (110) & $\mathrm{C}(2 \times 2)$ & $\mathrm{S}$ on $\mathrm{H}$ \\
\hline & Ir $\quad(110)$ & $\mathrm{C}(2 \times 2)$ & $\mathrm{O}$ on $\mathrm{B}$ \\
\hline & Ir (110) & $(2 \times 2)$ & $2 \mathrm{~S}$ on $\mathrm{H}$ \\
\hline \multirow[t]{4}{*}{444} & $\mathrm{Ni} \quad(100)$ & $(1 \times 1)$ & $\mathrm{Cu}$ on $\mathrm{H}$ \\
\hline & $\mathrm{Ni} \quad(100)$ & $\mathrm{C}(2 \times 2)$ & Se on $\mathrm{H}$ \\
\hline & $\mathrm{Ni}(100)$ & $(2 \times 2)$ & $2 \mathrm{C}$ on $\mathrm{H}$ \\
\hline & $\mathrm{Ni} \quad(100)$ & $(2 \times 2)$ & $\mathrm{O}$ on $\mathrm{H}$ \\
\hline$(444)$ & Pt (111) & $\mathrm{C}(4 \times 2)$ & $2 \mathrm{CO}$ on $\mathrm{T}$ or $\mathrm{B}$ \\
\hline 363 & $\mathrm{Ni} \quad(111)$ & $(2 \times 2)$ & $2 \mathrm{H}$ on $\mathrm{H}$ \\
\hline \multirow[t]{2}{*}{$\left(\begin{array}{lll}2 & 2 & 6\end{array}\right)$} & $\mathrm{Ag}(110)$ & $(2 \times 1)$ & $\mathrm{O}$ on $\mathrm{B}$ \\
\hline & $\mathrm{Ni}(110)$ & $(2 \times 2)$ & $\mathrm{S}$ on $\mathrm{H}$ \\
\hline 224 & Ta (100) & $(1 \times 3)$ & $\mathrm{O}$ on $\mathrm{H}$ \\
\hline
\end{tabular}

The adsorbed atoms A of many surface structures are ordered in a hexagonal or square net with self-coordination numbers $T_{1}, T_{2}, T_{3}$ of nearest, next-nearest and third A-A neighbors 666 or 444 (Table 2). This is obviously related to the hexagonal or square net of the substrate atoms of most structures. Some structures with $(666)$ or (4 4 4) values in brackets show that the hexagonal or square net of adsorbed atoms is approximated for other symmetries of substrate atoms (Table 2). A hexagonal net can also be found in incommensurate structures (like $\mathrm{Ag}$ (111) Xe) [7] or the 2D ordering of macromolecules or colloids without specific bonding to the Ag, water or glass surface. The honeycomb net with $T_{i}$ values 363 is observed for $\mathrm{H}$ atoms on $\mathrm{Ni}$ (111). The $\mathrm{O}$ atoms on $\mathrm{Ag}(110)$ with $b / a \approx 0.71$ or the $\mathrm{S}$ atoms on $\mathrm{Ni}(110)$ with $b / a \approx 0.62$ are close to the lattice complex 226 (b) of characteristic Wyckoff position 6 -a-d at $b / a=1 / \sqrt{3}$ (Table 1 ). The 224 values at $b / a=1 / 3$ are obtained for $\mathrm{O}$ atoms on $\mathrm{Ta}(100)$.

The hexagonal net ( 666 ) and square net (4 4 4) of adsorbed atoms correspond to circle packings with maximum density $[2,8]$. The density is decreased in the 363,226 or 224 lattice complexes.

The $2 \mathrm{D}$ Ni $(100) \mathrm{C}(2 \times 2) \mathrm{Na} / \mathrm{C}(2 \times 2) \mathrm{S}$ structure [7] with two square nets $(444)$ of $\mathrm{Na}$ and $\mathrm{S}$ atoms at translation $1 / 21 / 2$ (maximum distance be- 
tween $\mathrm{A}$ and $\mathrm{B}$ atoms) has the 2D ordering with maximum Madelung factor (Table 1). The Madelung factor is decreased from 1.6155 to 1.3789 in Ni (100) $(2 \times 2) \mathrm{Na} /(2 \times 2) \mathrm{S}$ with translation $1 / 20$ of the square nets. The maximum $\mathrm{MF}$ value for the combination of lattice complexes is obtained at different translations of $\mathrm{B}$ atoms. The $\mathrm{B}$ positions are such that a maximum number of them lies on the border of the A-A Dirichlet domain. The A and B atoms form lattice complexes like a square or honeycomb net of $\mathrm{A}$ and $\mathrm{B}$ atoms in Wyckoff position 11-a,b or 17-a. There are two groups of 2D lattice complexes with space groups 10-12 (square) or 13-17 (hexagonal). The lattice complexes of the same space group can be combined without distortion. The MF values of homogeneous structures with identical potential surfaces like $044 ; 1$ and 220 ; 1b of the 444 (square) net [2] are related:

$$
\begin{aligned}
& \operatorname{MF}(444 \mid 044 ; 1)=2 \operatorname{MF}(444 \mid 220 ; 1 b)(=1.6155), \\
& \operatorname{MF}(363 \mid 060 ; 1)=3 \operatorname{MF}(446 \mid 200 ; 2)(=1.5422), \\
& \operatorname{MF}(363 \mid 060 ; 1)=6 / 5 \operatorname{MF}(446 \mid 040 ; 2), \\
& \operatorname{MF}(363 \mid 060 ; 1)=1 / 2 \operatorname{MF}(A=666, \mathrm{~B}=363) .
\end{aligned}
$$

The last example shows a relation between $\mathrm{MF}$ values of an $\mathrm{AB}$ and $\mathrm{AB}_{2}$ structure (with A and B at Wyckoff positions 17-ab).

Rod-like molecules with rotational freedom (calamitic liquid crystals) are frequently ordered in two dimensions [9]. A hexagonal net (6 6 6) is observed for liquid crystals in hexatic B, smectic I, F, L or crystal B, J and G phases. The tilt of molecule axes in smectic I/crystal $\mathrm{J}$ or smectic $\mathrm{F} /$ crystal $\mathrm{G}$ phases is directed towards the top or bridge position of the hexagonal net. The twodimensional ordering of crystal $\mathrm{E}, \mathrm{K}$ or $\mathrm{H}$ phases is approximated by the (2 26 ), (2 6 4) or (2 4 6) complexes of Wyckoff letter 2-a-d with two orientations $\mathrm{A}$ and $\mathrm{B}$ (instead of two species). $\mathrm{AB}$ structures are also observed in smectic $\mathrm{C}_{\text {alt }}, \mathrm{C}_{d}, \mathrm{C}_{1}$ or $\mathrm{C}_{2}$ phases. Non-rotating molecules can be analyzed by different directions $\mathrm{A}, \mathrm{B}, \mathrm{C}$, etc. of the molecules depending on the symmetry elements of the space group [2]. The center atom of a molecule in the general Wyckoff position with coordinates $x y z$ has $T_{1}, T_{2}, T_{3}$ first, second and third neighbors. 2D tiles similar to Dirichlet domains are obtained, if the lines between A or B positions are intersected midway by vertical lines (vertical planes in $3 \mathrm{D}$ structures). The other atoms of the molecule are in these domains with different orientation $\mathrm{A}, \mathrm{B}, \mathrm{C}, \mathrm{D}$ depending on the symmetry. The A, B, C, D sequences of molecules frequently form 1D rows in different directions. The $\approx 60000$ entries of the Cambridge Structure Database with a single molecule in the triclinic unit cell $P 1$ have the same orientation in linear $\mathrm{A}_{\infty}$ chains (2 22 ) in [100], [010] and [001] directions [2,10]. The third neighbors $\left(T_{3}\right)$ form $\mathrm{A}_{\infty}$ rows in [110] direction of the triclinic unit cell of layered compounds. $\mathrm{AB}$ sequences are formed in compounds crystallizing in $P \overline{1}$ [10]. This alignment of molecules with $180^{\circ}$ rotation of the $\mathrm{B}$ position can be compared to antiferromagnetic ordering in magnetic compounds. The orientations $\mathrm{A}, \mathrm{B}$, 
$\mathrm{C}$ and $\mathrm{D}$ are observed in most organic molecules with frequently occurring space groups like $P c, C c, C 2, P 2_{1}(\mathrm{AB})$ or $C 2 / c, P 2_{1} / c, P 2_{1} 2_{1} 2_{1}, P c a 2_{1}$ and $P n a 2_{1}$ (ABCD) [11, 12]. Centrosymmetric molecules with space groups $C 2 / c$ or $P 2_{1} / c$ have two different orientations $\mathrm{A}$ and $\mathrm{B}$. The minimum values 111 are obtained in the oblique (monoclinic) space group $p 2(2 e)$. Symmetrical molecules like $\mathrm{C}_{6} \mathrm{Cl}_{6}$ or rotating $\alpha-\mathrm{N}_{2}$ with the center of the molecule in the special Wyckoff position $x=y=z=0$ form the 666 packing with increased density. The stacking of the Dirichlet domains of molecules without ionic or hydrogen bridge bonding can be compared with the formation of stone walls without cement. The Dirichlet domains of space groups with mirror planes will deteriorate. These space groups are very rare for organic molecules $[11,12]$.

\section{3D lattice complexes with increased $T_{i}$ values}

The self-coordination numbers $T_{1}, T_{2}, T_{3}$ of 3D lattice complexes with zero or one parameters could be determined in a similar way as outlined for $2 \mathrm{D}$ structures [13] (Table 3). The cubic lattice complexes with variable $x$ can degenerate at certain $x$ values as was outlined for $2 \mathrm{D}$ complexes. The tetragonal or hexagonal lattice complexes of space groups 75-194 degenerate to 2D lattice complexes like 444 (square net), 666 (hexagonal net), 446 (kagomé net), 363 (honeycomb net) or the 1D sequence 222 for small or large ratios of lattice constants $c / a$.

Most of the lattice complexes with $4 \leq T_{1} \leq 12$ are homogeneous sphere packings $[8,13]$. The nearest neighbors of layered structures or unstable sphere packings are on the meridian or one hemisphere. Layered structures and structures with $T_{1}<4$ are usually formed at attractive $\mathrm{A}-\mathrm{A}$ interactions like covalent bonding in $\mathrm{Cl}_{2}\left(T_{1}=1\right)$, sulfur chains $\left(T_{1}=2\right)$ or graphite $\left(T_{1}=3\right)$. Straight chains of A positions are rod packings [14].

Structures of the Inorganic Crystal Structure Database (ICSD) [15], standardized structure types (TYPIX) [16] or alloys [17] with one or two Wyckoff positions are analyzed for $T_{i}$ values (Table 4), if the positions of atoms can be approximated by the lattice complex with maximum $T_{i}$ values.

Some elements like $\mathrm{Cu}$ (12 6 24), W (8 6 12) or diamond (4 12 12) have the structure of undistorted lattice complexes. The same applies for homogeneous structures $\mathrm{A}_{x} \mathrm{~B}_{y}$ with identical neighborhood of $\mathrm{A}$ and $\mathrm{B}$ atoms like $\mathrm{NaCl}$ (12 6 24), $\mathrm{CsCl}$ (6 12 8) or NaTl (4 12 12). The electron configurations of the atoms are either spherical like $\mathrm{Na}$ and $\mathrm{Cl}$ or in accordance with the symmetry of the lattice complex like the $s p^{3}$ electron configuration of $\mathrm{C}$ atoms with $T_{1}=4 \mathrm{C}-\mathrm{C}$ bonds. Most lattice complexes however are distorted. Several reasons for the distortions can be recognized:

Jahn-Teller distortion: The $\mathrm{Co}^{2+}$ atoms of $\mathrm{CoO}$ (12 6 24) have a nonspherical $d^{7}$ electron configuration with different bond length in $c$ direction and $c / a=0.99$ of the tetragonally distorted $\mathrm{NaCl}$ structure. 
Table 3. Self-coordination values $T_{1}, T_{2}, T_{3}$ for 3D lattice complexes of characteristic Wyckoff positions [5] with less than two parameters $c / a$ or $x$ in space groups 75-194 or 195-230, respectively including invariant cubic lattice complexes (second origin of space groups).

\begin{tabular}{|c|c|c|c|c|c|c|c|}
\hline$c / a$ & $T_{i}$ & $c / a$ & $T_{i}$ & $c / a$ & $T_{i}$ & $c / a$ & $T_{i}$ \\
\hline \multicolumn{2}{|c|}{ 123-a-d } & \multicolumn{2}{|c|}{ 141-c,d } & $1 / 2$ & 446 & \multicolumn{2}{|c|}{ 191-c,d } \\
\hline & 222 & & 222 & $\sqrt{6} / 4$ & 488 & & 222 \\
\hline $1 / 3$ & 226 & $\sqrt{2 / 143}$ & 226 & $\sqrt{3} / 2$ & 4410 & $1 / \sqrt{27}$ & 225 \\
\hline $1 / 2$ & 268 & $\sqrt{2 / 63}$ & 264 & $\sqrt{6} / 2$ & 8616 & $1 / \sqrt{12}$ & 256 \\
\hline $1 / \sqrt{3}$ & 2410 & $\sqrt{2 / 55}$ & 246 & $\sqrt{15} / 2$ & 4410 & $1 / 3$ & 238 \\
\hline 1 & 6128 & $\sqrt{2 / 15}$ & 642 & $\sqrt{33} / 2$ & 4410 & $1 / \sqrt{3}$ & 566 \\
\hline$\sqrt{2}$ & 468 & $\sqrt{2} / 3$ & 426 & & 446 & 1 & 389 \\
\hline \multirow[t]{2}{*}{2} & 446 & $1 / 2$ & 444 & \multicolumn{2}{|c|}{ 180/181-c,d } & $2 / \sqrt{3}$ & 365 \\
\hline & 444 & $\sqrt{2 / 7}$ & 426 & & 222 & & 363 \\
\hline \multicolumn{2}{|c|}{ 139-a,b } & $\sqrt{2}$ & $\begin{array}{lll}6 \quad 12 \quad 12\end{array}$ & $3 / \sqrt{320}$ & 226 & \multicolumn{2}{|c|}{ 191-f,g } \\
\hline \multicolumn{2}{|c|}{222} & & $\begin{array}{r}2412 \\
24\end{array}$ & $3 / \sqrt{140}$ & 264 & & 222 \\
\hline$\sqrt{2 / 35}$ & 2210 & \multirow{2}{*}{\multicolumn{2}{|c|}{ 166-a,b }} & $3 / \sqrt{128}$ & 246 & $1 / 6$ & 226 \\
\hline$\sqrt{2 / 15}$ & 2108 & & & $3 / \sqrt{32}$ & 644 & $1 / 4$ & 268 \\
\hline $1 / 2$ & 286 & & 222 & $3 / \sqrt{20}$ & 464 & $1 / \sqrt{12}$ & 2410 \\
\hline$\sqrt{2 / 3}$ & 1048 & $\sqrt{3 / 80}$ & 228 & $3 \sqrt{6} / 8$ & 446 & $1 / 2$ & 684 \\
\hline 1 & $\begin{array}{lll}8 & 6 & 12\end{array}$ & $\sqrt{3 / 35}$ & 286 & $3 \sqrt{2} / 4$ & 444 & $\sqrt{2} / 2$ & 4212 \\
\hline$\sqrt{2}$ & 12624 & $\sqrt{3 / 32}$ & 268 & $3 \sqrt{3} / 4$ & 4410 & $\sqrt{3} / 2$ & 4614 \\
\hline$\sqrt{6}$ & 41220 & $\sqrt{3 / 8}$ & 8612 & $3 / 2$ & 4104 & 1 & 448 \\
\hline \multirow[t]{2}{*}{$\sqrt{14}$} & 4412 & $\sqrt{3 / 5}$ & 686 & $3 \sqrt{3} / 2$ & 1048 & & 446 \\
\hline & 444 & 1 & 668 & $9 / 2$ & 6410 & \multicolumn{2}{|c|}{ 194-c,d } \\
\hline \multicolumn{2}{|c|}{$141-a, b$} & $\sqrt{3 / 2}$ & 6128 & $3 \sqrt{11} / 2$ & 6104 & & 222 \\
\hline & 222 & $\sqrt{3}$ & $\begin{array}{rrr}6 & 6 & 12 \\
12 & 6 & 24\end{array}$ & $3 \sqrt{15} / 2$ & 6610 & $2 / \sqrt{105}$ & 228 \\
\hline $2 / \sqrt{143}$ & 226 & $\sqrt{6}$ & $\begin{array}{rrr}12 & 6 & 24 \\
6 & 6 & 12\end{array}$ & & 666 & $2 / \sqrt{45}$ & 286 \\
\hline $2 / \sqrt{63}$ & 264 & $\begin{array}{l}\sqrt{15} \\
\sqrt{24}\end{array}$ & $\begin{array}{rrrr} & 6 & 0 & 12 \\
6 & 12 & 12\end{array}$ & \multicolumn{2}{|c|}{ 191-a,b } & $2 / \sqrt{21}$ & 268 \\
\hline $2 / \sqrt{55}$ & 246 & & $\begin{array}{r}61212 \\
666\end{array}$ & & 222 & $2 / 3$ & 866 \\
\hline $2 / \sqrt{15}$ & 648 & \multirow{2}{*}{\multicolumn{2}{|c|}{ 166-d,e }} & $1 / 3$ & 228 & $\sqrt{6} / 3$ & 626 \\
\hline $2 / \sqrt{7}$ & 468 & & & $1 / 2$ & 2812 & 1 & 686 \\
\hline$\sqrt{2 / 3}$ & 4410 & & 222 & $1 / \sqrt{3}$ & 2614 & $4 / 3$ & 668 \\
\hline $2 / \sqrt{5}$ & 4122 & $\sqrt{3 / 320}$ & 226 & 1 & 8126 & $\sqrt{8 / 3}$ & 1262 \\
\hline$\sqrt{2}$ & $\begin{array}{lll}4 & 12 & 12\end{array}$ & $\sqrt{3 / 140}$ & 264 & $\sqrt{2}$ & $\begin{array}{lll}62 & 28\end{array}$ & $\sqrt{20 / 3}$ & 6612 \\
\hline 2 & 4416 & $\sqrt{3 / 128}$ & 246 & $\sqrt{3}$ & $\begin{array}{lll}6 & 8 & 18\end{array}$ & $\sqrt{32 / 3}$ & $\begin{array}{lll}6 & 12 & 12\end{array}$ \\
\hline \multirow{2}{*}{$\sqrt{12}$} & 8124 & $\sqrt{3 / 32}$ & 648 & 2 & 668 & & 666 \\
\hline & 444 & $\sqrt{3 / 20}$ & 464 & & 666 & & \\
\hline
\end{tabular}

Lone electron pairs: The neighborhood of $\mathrm{Tl}^{+}$atoms in $\mathrm{TlF}$ with $c / a=1.14$ of the same structure type is non-spherical with a lone electron pair. A different tetragonal distortion with $c / a^{\prime}=1.05$ is found in the high pressure modification of GeP. (The $a^{\prime}$ value of the lattice complex is different from the $a$ value of the hexagonal cell.) Trigonally distorted $\mathrm{NaCl}$ structures with $c / a=2.57$ or 
Table 3. continued.

\begin{tabular}{|c|c|c|c|c|c|}
\hline$x$ & $T_{i}$ & $x$ & $T_{i}$ & $x$ & $T_{i}$ \\
\hline \multicolumn{2}{|c|}{ 198-a } & \multicolumn{2}{|c|}{ 211-i } & \multicolumn{2}{|c|}{ 216-e } \\
\hline 0 & 12624 & $(3-\sqrt{5}) / 8$ & 126 & $1 / 8$ & 61212 \\
\hline$(3-\sqrt{5}) / 8$ & 6612 & $(-1+\sqrt{2}) / 4$ & 324 & \multicolumn{2}{|c|}{ 217-c } \\
\hline $1 / 8$ & 6126 & $(-3+\sqrt{12}) / 4$ & 234 & $(2-\sqrt{2}) / 8$ & 3614 \\
\hline \multicolumn{2}{|c|}{ 199-a } & $1 / 8$ & 414 & $3 / 16$ & 968 \\
\hline 0 & 6128 & $\sqrt{3} / 12$ & 225 & $1 / 4$ & 6128 \\
\hline $1 / 16$ & 396 & \multicolumn{2}{|c|}{ 212/213-a,b } & \multicolumn{2}{|c|}{$220-a, b$} \\
\hline $1 / 8$ & 366 & - & 6126 & - & 848 \\
\hline \multicolumn{2}{|c|}{ 199-b } & \multicolumn{2}{|c|}{ 212-c } & \multicolumn{2}{|c|}{ 220-c } \\
\hline$-1 / 8$ & 848 & $-1 / 8$ & 366 & 0 & $8 \quad 6 \quad 12$ \\
\hline$(3-\sqrt{13}) / 8$ & 462 & $(1-\sqrt{2}) / 4$ & 367 & $(2-\sqrt{2}) / 16$ & $\begin{array}{r}0 \\
563\end{array}$ \\
\hline 0 & 428 & $(5-\sqrt{30}) / 8$ & 376 & $1 / 8$ & $\begin{array}{lll}32 & 12\end{array}$ \\
\hline$(3-\sqrt{5}) / 8$ & 426 & 0 & 41212 & 22 & \\
\hline $1 / 8$ & 444 & $<1 / 8$ & 136 & 0 & 144 \\
\hline \multicolumn{2}{|c|}{ 200-f,g } & \multicolumn{2}{|c|}{ 212-d } & $(-3+\sqrt{11}) / 8$ & 542 \\
\hline$(5-\sqrt{21}) / 4$ & 189 & 0 & 444 & $(-1+\sqrt{2}) / 4$ & 454 \\
\hline$(3-\sqrt{5}) / 4$ & 198 & $5 / 24$ & 262 & $(-2+\sqrt{6}) / 4$ & $\begin{array}{ll}4 & 54 \\
4 & 45\end{array}$ \\
\hline $1 / 4$ & 2816 & $(-1+\sqrt{33}) / 16$ & 622 & $\begin{array}{c}(-2+\sqrt{ } 0) / 4 \\
1 / 8\end{array}$ & $\begin{array}{lll}4 & 4 & 3 \\
482\end{array}$ \\
\hline \multicolumn{2}{|c|}{ 204-e } & $3 / 8$ & 4108 & \multirow{2}{*}{\multicolumn{2}{|c|}{ 221-a,b }} \\
\hline $1 / 8$ & 1412 & \multirow{2}{*}{\multicolumn{2}{|c|}{ 214-a,b }} & & \\
\hline$(-1+\sqrt{3}) / 4$ & $\begin{array}{lll}5 & 8 & 1\end{array}$ & & & גר1 & $\begin{array}{llll}6 & 12 & 8\end{array}$ \\
\hline$(3-\sqrt{5}) / 4$ & 419 & - & 366 & \multicolumn{2}{|c|}{ 221-c,d } \\
\hline $1 / 4$ & 428 & \multicolumn{2}{|c|}{ 214-c,d } & - & 8616 \\
\hline 205 & & - & 444 & \multicolumn{2}{|c|}{ 221-e } \\
\hline$(-1+\sqrt{5}) / 8$ & 763 & \multicolumn{2}{|c|}{ 214-e } & $1 / 4$ & 428 \\
\hline$(-1+\sqrt{3}) / 4$ & 679 & 214 & 8612 & $(2-\sqrt{2}) / 2$ & $\begin{array}{lll}5 & 1 & 8\end{array}$ \\
\hline$(-3+\sqrt{15}) / 4$ & 667 & & 80012 & $(-1+\sqrt{3}) / 2$ & 149 \\
\hline $1 / 4$ & 6128 & \multicolumn{2}{|c|}{ 214-f } & \multicolumn{2}{|c|}{ 221-g } \\
\hline \multicolumn{2}{|c|}{ 206-c } & $\begin{array}{c}-1 / 8 \\
(1-\sqrt{3}) / 8\end{array}$ & $\begin{array}{lll}4 & 8 & 2 \\
2 & 2 & 5\end{array}$ & $(-1+\sqrt{3}) / 4$ & 334 \\
\hline$(3-\sqrt{5}) / 8$ & 137 & $(2-\sqrt{5}) / 4$ & 234 & $1 / 4$ & 6128 \\
\hline$(-1+\sqrt{2}) / 4$ & 416 & $-1 / 24$ & 216 & 22 & \\
\hline $1 / 8$ & $\begin{array}{ll}3212 \\
2\end{array}$ & 0 & 344 & $(-1+\sqrt{2}) / 2$ & 231 \\
\hline \multicolumn{2}{|c|}{ 206-d } & \multicolumn{2}{|c|}{ 214-h } & $1 / 4$ & 428 \\
\hline 0 & $\begin{array}{lll}8 & 6 & 16\end{array}$ & $(-3+\sqrt{12}) / 8$ & 342 & \multicolumn{2}{|c|}{ 221-i } \\
\hline$(3-\sqrt{5}) / 8$ & 446 & $(-1+\sqrt{8}) / 8$ & 424 & $(-2+\sqrt{6}) / 2$ & 426 \\
\hline $1 / 8$ & 482 & $1 / 4$ & 248 & $1 / 4$ & 448 \\
\hline 208- & & $(-1+\sqrt{33}) / 16$ & 226 & $(2-\sqrt{2}) / 2$ & 676 \\
\hline$(3-\sqrt{8}) / 4$ & 162 & $(1+\sqrt{17}) / 16$ & 262 & $1 / 3$ & 254 \\
\hline$(-3+\sqrt{12}) / 4$ & 342 & $3 / 8$ & 9418 & 223 & \\
\hline 210 & & 215 & & - & 2816 \\
\hline 0 & 2816 & $(2-\sqrt{2}) / 4$ & 369 & 223 & \\
\hline$(3-\sqrt{8}) / 8$ & 442 & $1 / 4$ & 12624 & $1 / 8$ & 224 \\
\hline
\end{tabular}


Table 3. continued.

\begin{tabular}{|c|c|c|c|c|c|}
\hline$x$ & $T_{i}$ & $x$ & $T_{i}$ & $x$ & $T_{i}$ \\
\hline \multicolumn{2}{|c|}{ 223-j } & \multicolumn{2}{|c|}{ 227-f } & \multicolumn{2}{|c|}{ 229-h } \\
\hline$(-3+\sqrt{12}) / 2$ & 234 & $>1 / 8$ & 414 & $3 / 16$ & 428 \\
\hline$(3-\sqrt{6}) / 4$ & 414 & $(-1+\sqrt{10}) / 8$ & 452 & $(4-\sqrt{10}) / 4$ & 466 \\
\hline$(-2+\sqrt{7}) / 4$ & 225 & $5 / 16$ & 834 & $1 / 4$ & 8616 \\
\hline \multirow{2}{*}{\multicolumn{2}{|c|}{ 224-e }} & $(-1+\sqrt{14}) / 8$ & 446 & $(2-\sqrt{2}) / 2$ & 462 \\
\hline & & $3 / 8$ & 488 & $1 / 3$ & 425 \\
\hline \multicolumn{2}{|c|}{$224-i, j$} & \multicolumn{2}{|c|}{ 227-h } & $\begin{array}{c}\sqrt{8} / 8 \\
(4-\sqrt{6}) / 4\end{array}$ & $\begin{array}{lll}6 & 1 & 4 \\
2 & 5 & 8\end{array}$ \\
\hline $1 / 8$ & 222 & $\begin{array}{l}1 / 8 \\
1 / 6\end{array}$ & $\begin{array}{lll}4 & 2 & 8 \\
2 & 2 & 3\end{array}$ & \multicolumn{2}{|c|}{ 229-i } \\
\hline $\begin{array}{c}(2-\sqrt{3}) / 2 \\
1 / 6\end{array}$ & $\begin{array}{lll}2 & 3 & 1 \\
3 & 6 & 3\end{array}$ & \multicolumn{2}{|c|}{ 228-g } & $1 / 12$ & 232 \\
\hline \multicolumn{2}{|c|}{$225-\mathbf{a}, \mathbf{b}$} & $1 / 8$ & 428 & $(-1+\sqrt{2}) / 4$ & 432 \\
\hline $\begin{array}{r}225 \\
-\quad\end{array}$ & 12624 & $1 / 6$ & 624 & $\begin{array}{c}1 / 8 \\
(2-\sqrt{2}) / 4\end{array}$ & $\begin{array}{lll}2 & 2 & 4 \\
2 & 2 & 3\end{array}$ \\
\hline \multicolumn{2}{|c|}{ 225-e } & 22 & 8612 & \multicolumn{2}{|c|}{ 230-b } \\
\hline $\begin{array}{c}(-1+\sqrt{2}) / 2 \\
1 / 4\end{array}$ & $\begin{array}{rr}45 & 4 \\
8 & 616\end{array}$ & \multicolumn{2}{|c|}{ 229-b } & \multicolumn{2}{|c|}{ 230-c } \\
\hline \multicolumn{2}{|c|}{ 225-f } & \multicolumn{2}{|c|}{ 229-d } & 230 & 482 \\
\hline $\begin{array}{c}(-2+\sqrt{6}) / 4 \\
1 / 8\end{array}$ & $\begin{array}{lll}3 & 3 & 4 \\
3 & 6 & 4\end{array}$ & 22 & 428 & \multicolumn{2}{|c|}{ 230-d } \\
\hline$(2-\sqrt{2}) / 4$ & 661 & \multicolumn{2}{|c|}{ 229-e } & \multirow{2}{*}{\multicolumn{2}{|c|}{ 230-e }} \\
\hline \multicolumn{2}{|c|}{ 225-h,i } & $(2-\sqrt{2}) / 4$ & 419 & & \\
\hline$(2-\sqrt{3}) / 2$ & 425 & $1 / 4$ & $\begin{array}{lll}4 & 2 & 8 \\
5 & 8 & 1\end{array}$ & $\begin{array}{c}1 / 16 \\
(-1+\sqrt{7}) / 16\end{array}$ & $\begin{array}{lll}2 & 3 & 3 \\
1 & 4 & 3\end{array}$ \\
\hline $\begin{array}{c}(2-\sqrt{2}) / 4 \\
1 / 6\end{array}$ & 434 & $\begin{array}{c}(2-\sqrt{2}) / 2 \\
3 / 8\end{array}$ & $\begin{array}{rrr}5 & 8 & 1 \\
1 & 12 & 8\end{array}$ & $\begin{array}{r}230 \\
230\end{array}$ & \\
\hline $\begin{array}{c}1 / 6 \\
(3-\sqrt{5}) / 4\end{array}$ & $\begin{array}{lll}5 & 2 & 12 \\
1 & 4 & 10\end{array}$ & \multicolumn{2}{|c|}{ 229-f } & 0 & 488 \\
\hline \multicolumn{2}{|c|}{$227-a, b$} & $1 / 8$ & 332 & $(-3+\sqrt{11}) / 8$ & 125 \\
\hline _ & $\begin{array}{lll}4 & 12 \quad 12\end{array}$ & $(3-\sqrt{6}) / 4$ & 341 & \multicolumn{2}{|c|}{ 230-g } \\
\hline \multicolumn{2}{|c|}{ 227-c,d } & $(3-\sqrt{3}) / 8$ & 431 & $(-3+\sqrt{12}) / 8$ & 344 \\
\hline & $612 \quad 12$ & $3 / 16$ & 139 & $1 / 4$ & 2816 \\
\hline 09 & $\begin{array}{llll}6 & 12 & 12\end{array}$ & \multicolumn{2}{|c|}{ 229-g } & $(4-\sqrt{3}) / 8$ & 622 \\
\hline \multicolumn{2}{|c|}{ 227-e } & & $(1+\sqrt{17}) / 16$ & 426 \\
\hline$(-2+\sqrt{6}) / 8$ & 463 & $(2-\sqrt{2}) / 4$ & $\begin{array}{lll}3 & 1 & 4\end{array}$ & $3 / 8$ & 496 \\
\hline $1 / 4$ & 12624 & $\begin{array}{l}(-1+\sqrt{3}) / 4 \\
(-14) / 4\end{array}$ & $\begin{array}{lll}3 & 1 & 4 \\
1 & 2 & 5\end{array}$ & $\begin{array}{c}(8-\sqrt{23}) / 8 \\
5 / 12\end{array}$ & $\begin{array}{lll}5 & 2 & 4 \\
1 & 6 & 4\end{array}$ \\
\hline
\end{tabular}

2.50 instead of 2.45 are found in $\mathrm{GeTe}$ or $\mathrm{BiO}$ with lone electron pairs of $\mathrm{Ge}^{2+}$ or $\mathrm{Bi}^{2+}$.

Non-invariant sphere packings: The $c / a=0.539$ of Sn or $c / a=0.831$ of $\mathrm{Pa}$ are close to $c / a=0.516$ of the (6 48$)$ or to $c / a=0.817$ of the (10 48$)$ sphere packing. The same applies for $x=0.1667$ or $x=0.1003$ values of $\mathrm{C}$ or $\gamma$-Si in the (4 31 ) or (4 14 ) sphere packings with $x=0.1585$ or 0.1036 values. The 
Table 4a. Self-coordination values $T_{1}, T_{2}, T_{3}$ of $\mathrm{A}$ and $\mathrm{B}$ atoms in $\mathrm{A}$ or $\mathrm{A}_{x} \mathrm{~B}_{y}$ structure types with one or two characteristic Wyckoff positions [5] of Table 3. The $T_{i}$ values in brackets are approximated in the experimental structures.

\begin{tabular}{|c|c|c|c|c|c|c|c|}
\hline A & B & $\mathrm{A}_{x} \mathrm{~B}_{y}$ & SG-WS & A & B & $\mathrm{A}_{x} \mathrm{~B}_{y}$ & SG-WS \\
\hline 12624 & - & $\mathrm{Cu}$ & $225-a$ & 8612 & - & W & $229-\mathrm{a}$ \\
\hline$\left(\begin{array}{lll}12 & 6 & 24\end{array}\right)$ & - & $(\mathrm{Al}, \mathrm{Zn})$ & 166-a & 8612 & 6128 & $\mathrm{Pt} \mathrm{Hg} \mathrm{H}_{4}$ & $229-\mathrm{ac}$ \\
\hline$\left(\begin{array}{lll}12 & 6 & 24\end{array}\right)$ & - & In & $139-\mathrm{a}$ & 8612 & $\left(\begin{array}{lll}4 & 12 & 6\end{array}\right)$ & $\mathrm{Si} \mathrm{F}_{4}$ & 208-ag \\
\hline (12 624$)$ & - & $\mathrm{N}_{2}$ & $198-\mathrm{a}$ & 8612 & 2816 & $\mathrm{Si} \mathrm{Cr}_{3}$ & $223-\mathrm{ac}$ \\
\hline 12624 & 12624 & $\mathrm{Zn} \mathrm{S}$ & 216-ac & 848 & - & $\mathrm{Ga}$ & $220-\mathrm{a}$ \\
\hline 12624 & 12624 & $\mathrm{NaCl}$ & $225-a b$ & 848 & $\left(\begin{array}{lll}5 & 6 & 3\end{array}\right)$ & $\mathrm{Eu}_{3} \mathrm{~S}_{4}$ & $220-\mathrm{ac}$ \\
\hline$\left(\begin{array}{lll}12 & 6 & 24\end{array}\right)$ & $\left(\begin{array}{lll}12 & 6 & 24\end{array}\right)$ & $\mathrm{Co} \mathrm{O}$ & 139-ba & 848 & $\left(\begin{array}{lll}3 & 2 & 12\end{array}\right)$ & $\mathrm{Th}_{3} \mathrm{P}_{4}$ & $220-\mathrm{ac}$ \\
\hline (12 6 24) & (12 624$)$ & $\mathrm{Ge} \mathrm{Te}$ & $160-$-аa & $(834)$ & 61212 & $\mathrm{~F}_{3} \mathrm{Fe}$ & $227-\mathrm{fc}$ \\
\hline 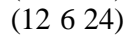 & $(12624)$ & Ge P & 107-aа & $\left(\begin{array}{lll}7 & 6 & 3\end{array}\right)$ & - & $\mathrm{N}_{2}$ & $205-c$ \\
\hline 12624 & 8612 & $\mathrm{O} \mathrm{Cu}{ }_{2}$ & $224-a b$ & $\left(\begin{array}{lll}6 & 12 & 12\end{array}\right)$ & $\left(\begin{array}{lll}6 & 12 & 12\end{array}\right)$ & $\mathrm{Pt} \mathrm{Cu}$ & 166-ba \\
\hline$\left(\begin{array}{lll}12 & 6 & 24\end{array}\right)$ & $\left(\begin{array}{lll}8 & 3 & 4\end{array}\right)$ & $\mathrm{As}_{2} \mathrm{O}_{3}$ & 227-ef & 61212 & 41212 & $\mathrm{Cu}_{2} \mathrm{Mg}$ & $227-\mathrm{cb}$ \\
\hline 12624 & $\left(\begin{array}{lll}7 & 6 & 3\end{array}\right)$ & $\mathrm{Fe} \mathrm{S}_{2}$ & $205-\mathrm{ac}$ & 61212 & 41212 & $\mathrm{O}_{2} \mathrm{Si}$ & 227-ca \\
\hline 12624 & $\left(\begin{array}{lll}7 & 6 & 3\end{array}\right)$ & $\mathrm{C} \mathrm{O}_{2}$ & $205-\mathrm{ac}$ & 6128 & - & Po & $221-\mathrm{a}$ \\
\hline$\left(\begin{array}{lll}12 & 6 & 24\end{array}\right)$ & 61212 & $\mathrm{Ti}_{2} \mathrm{C}$ & $227-\mathrm{ec}$ & 6128 & 6128 & $\mathrm{Cs} \mathrm{Cl}$ & $221-a b$ \\
\hline 12624 & 6128 & $\mathrm{CaF}_{2}$ & $225-\mathrm{ac}$ & $\left(\begin{array}{lll}6 & 12 & 8\end{array}\right)$ & $\left(\begin{array}{lll}6 & 12 & 8\end{array}\right)$ & $\mathrm{Ti} \mathrm{Cu}$ & $123-\mathrm{da}$ \\
\hline 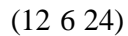 & 6128 & $\mathrm{Fe}_{4} \mathrm{C}$ & 215-еa & 6128 & $\left(\begin{array}{lll}5 & 1 & 8\end{array}\right)$ & $\mathrm{Ca} \mathrm{B}_{6}$ & 221-af \\
\hline (12 6 24) & $\left(\begin{array}{lll}6 & 12 & 8\end{array}\right)$ & $\mathrm{Pt} \mathrm{S}$ & 131-ce & 6128 & 488 & $\mathrm{O}_{4} \mathrm{Pt}_{3}$ & 229-cb \\
\hline$\left(\begin{array}{lll}12 & 6 & 24\end{array}\right)$ & $\left(\begin{array}{l}6 \\
6\end{array}\right.$ & $\mathrm{Th} \mathrm{H}_{2}$ & $139-\mathrm{ad}$ & 6128 & 2816 & $\mathrm{O}_{4} \mathrm{Pt}_{3}$ & $223-\mathrm{ec}$ \\
\hline (12 624$)$ & $\left(\begin{array}{lll}6 & 6 & 12\end{array}\right)$ & $\mathrm{N}_{2}$ & 198-аa & $\left(\begin{array}{lll}6 & 12 & 8\end{array}\right)$ & $(24$ 10) & $\mathrm{Hg}_{2} \mathrm{Pt}$ & 123-ea \\
\hline (12 624$)$ & $\left(\begin{array}{lll}6 & 6 & 12\end{array}\right)$ & $\mathrm{CO}$ & 198-аa & 6126 & $(376)$ & $\mathrm{Sr} \mathrm{Si}_{2}$ & $213-\mathrm{ac}$ \\
\hline 12624 & $\left(\begin{array}{lll}5 & 2 & 12\end{array}\right)$ & $\mathrm{U} \mathrm{B}_{12}$ & 225-ai & $\left(\begin{array}{lll}6 & 8 & 18\end{array}\right)$ & $\left(\begin{array}{lll}6 & 8 & 18\end{array}\right)$ & Li Rh & $187-d a$ \\
\hline 12624 & $\left(\begin{array}{l}4 \\
4\end{array} 126\right)$ & $\mathrm{C} \mathrm{O}_{2}$ & 201-be & $\left(\begin{array}{lll}6 & 8 & 18\end{array}\right)$ & 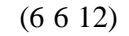 & $\mathrm{Nd}$ & $194-\mathrm{ac}$ \\
\hline 12624 & $\left(4{ }^{2} 6\right)$ & $\mathrm{Ca} \mathrm{C}_{2}$ & 201-be & $\left(\begin{array}{lll}6 & 6 & 12\end{array}\right)$ & - & $\mathrm{Hg}$ & $166-\mathrm{a}$ \\
\hline 12624 & 488 & $\mathrm{Ag}_{2} \mathrm{O}_{3}$ & 224-bd & $\left(\begin{array}{lll}6 & 6 & 12\end{array}\right)$ & $\left(\begin{array}{lll}6 & 6 & 12\end{array}\right)$ & $\mathrm{Fe} \mathrm{Si}$ & 198-аa \\
\hline 12624 & $\left(\begin{array}{lll}2 & 2 & 4\end{array}\right)$ & $\mathrm{PH}_{3}$ & 208-bi & $\left(\begin{array}{lll}6 & 6 & 12\end{array}\right)$ & $\left(\begin{array}{lll}6 & 6 & 12\end{array}\right)$ & $\mathrm{Hg}$ In & $166-a b$ \\
\hline$\left(\begin{array}{ll}12 & 6\end{array}\right)$ & - & $\mathrm{Mg}$ & $194-c$ & $\left(\begin{array}{lll}6 & 6 & 12\end{array}\right)$ & $\left(\begin{array}{lll}6 & 6 & 12\end{array}\right)$ & $\mathrm{B} N$ & 194-cd \\
\hline 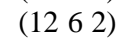 & $(1262)$ & $\mathrm{C}$ & 186-bb & $\left(\begin{array}{lll}6 & 6 & 12\end{array}\right)$ & $\left(\begin{array}{lll}6 & 2 & 18\end{array}\right)$ & $\mathrm{C}$ & 194-cb \\
\hline 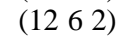 & $\left(\begin{array}{ll}12 & 6\end{array}\right)$ & Zn S & 186-bb & 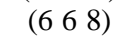 & - & Po & $166-\mathrm{a}$ \\
\hline 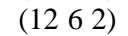 & $\left(\begin{array}{l}8 \\
12\end{array}\right)$ & $\mathrm{S} \mathrm{Fe}$ & 194-ca & 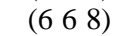 & $\left(\begin{array}{lll}2 & 6 & 14\end{array}\right)$ & As Ni & 194-ca \\
\hline$\left(\begin{array}{ll}12 & 6\end{array}\right)$ & 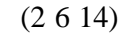 & S Co & 194-ca & $(648)$ & - & $\mathrm{Sn}$ & 141-b \\
\hline$(1048)$ & - & $\mathrm{Pa}$ & $139-\mathrm{a}$ & $\left(\begin{array}{lll}6 & 2 & 2\end{array}\right)$ & (3 76 ) & $\beta-\mathrm{Mn}$ & $213-\mathrm{dc}$ \\
\hline 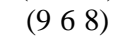 & 8612 & $\mathrm{~F}_{4} \mathrm{Si}$ & $217-\mathrm{ca}$ & $(566)$ & $\left(\begin{array}{lll}2 & 6 & 14\end{array}\right)$ & $\mathrm{Hg}_{2} \mathrm{U}$ & 191-da \\
\hline$\left(\begin{array}{lll}9 & 6 & 8\end{array}\right)$ & (3 6 14) & Li B & $217-\mathrm{cc}$ & $(566)$ & $\left(\begin{array}{l}2 \\
6\end{array} 14\right)$ & $\mathrm{Ti}$ & 191-da \\
\hline$\left(\begin{array}{lll}8 & 12 & 6\end{array}\right)$ & - & $(\mathrm{Sn}, \mathrm{Hg})$ & $191-\mathrm{a}$ & $\left(\begin{array}{lll}5 & 6 & 3\end{array}\right)$ & $(542)$ & $\mathrm{Pu}_{2} \mathrm{C}_{3}$ & $220-\mathrm{cd}$ \\
\hline$\left(\begin{array}{lll}8 & 12 & 6\end{array}\right)$ & $(8126)$ & W C & $187-\mathrm{ad}$ & 41212 & - & $\mathrm{C}$ & $227-\mathrm{a}$ \\
\hline$\left(\begin{array}{lll}8 & 12 & 6\end{array}\right)$ & $\left(\begin{array}{lll}3 & 8 & 9\end{array}\right)$ & Mo B 2 & 191-ad & 41212 & 41212 & $\mathrm{Na} \mathrm{Tl}$ & $227-\mathrm{ab}$ \\
\hline 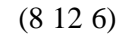 & 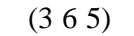 & $\mathrm{Al} \mathrm{B}_{2}$ & $191-\mathrm{ad}$ & $\left(\begin{array}{lll}4 & 6 & 8\end{array}\right)$ & $\left(\begin{array}{lll}4 & 6 & 8\end{array}\right)$ & $\mathrm{Cu} \mathrm{Au}$ & $123-\mathrm{ad}$ \\
\hline$\left(\begin{array}{lll}8 & 12 & 4\end{array}\right)$ & $\left(\begin{array}{lll}8 & 12 & 4\end{array}\right)$ & $\mathrm{Nb} \mathrm{P}$ & $141-a b$ & $(44$ 16) & $(44$ 16) & $\mathrm{UPb}$ & $141-\mathrm{ab}$ \\
\hline 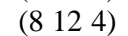 & 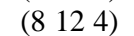 & $\mathrm{Nb} \mathrm{As}$ & 109-аa & $(446)$ & $(446)$ & $\mathrm{Pd} \mathrm{O}$ & $75-a b$ \\
\hline 8616 & 8616 & $\mathrm{Nb} \mathrm{O}$ & $221-\mathrm{cd}$ & $\left(\begin{array}{lll}4 & 3 & 1\end{array}\right)$ & - & $\mathrm{C}$ & 229-f \\
\hline 8616 & 6128 & $\mathrm{Cu}_{3} \mathrm{Au}$ & 221-ca & $\left(\begin{array}{lll}4 & 1 & 6\end{array}\right)$ & - & $\mathrm{Si}$ & 206-c \\
\hline 8616 & 6128 & $\mathrm{O}_{3} \mathrm{Re}$ & 221-da & $(396)$ & $(396)$ & $\mathrm{U}$ Co & 199-аa \\
\hline$(8616)$ & $\left(\begin{array}{lll}6 & 12 & 8\end{array}\right)$ & $\mathrm{F}_{3} \mathrm{Ti}$ & 166-da & & & & \\
\hline
\end{tabular}


Table 4b. The same as Table $4 a$ for $\mathrm{A}_{x} \mathrm{~B}_{y} \mathrm{C}_{z}$.

\begin{tabular}{|c|c|c|c|c|}
\hline A & B & $\mathrm{C}$ & $\mathrm{A}_{x} \mathrm{~B}_{y} \mathrm{C}_{z}$ & SG-WS \\
\hline 12624 & 12624 & 12624 & $\mathrm{Mg} \mathrm{Ag} \mathrm{As}$ & $216-a b c$ \\
\hline 12624 & 12624 & 8616 & $\mathrm{Cu} \mathrm{Pt} \mathrm{Pt}_{6}$ & 225-abd \\
\hline 12624 & $12 \quad 6 \quad 24$ & $\left(\begin{array}{lll}6 & 12 & 12\end{array}\right)$ & $\mathrm{Mg} \mathrm{Sn} \mathrm{Cu}$ & 216-ace \\
\hline 12624 & 12624 & $\begin{array}{lll}6 & 12 & 8\end{array}$ & $\mathrm{Al} \mathrm{MnCu}_{2}$ & $225-a b c$ \\
\hline$\left(\begin{array}{lll}12 & 6 & 24\end{array}\right)$ & $\left(\begin{array}{lll}12 & 6 & 24\end{array}\right)$ & $\left(\begin{array}{lll}4 & 6 & 8\end{array}\right)$ & V Sn $\mathrm{Rh}_{2}$ & 139-abd \\
\hline 12624 & $\left(\begin{array}{lll}8 & 6 & 16\end{array}\right)$ & 6128 & $\mathrm{Pt} \mathrm{Cl}_{6} \mathrm{~K}_{2}$ & 225-aec \\
\hline$\left(\begin{array}{lll}12 & 6 & 24\end{array}\right)$ & 8616 & 6128 & $\mathrm{~S}_{4} \mathrm{Cu}_{3} \mathrm{As}$ & 215-eca \\
\hline$\left(\begin{array}{lll}12 & 6 & 24\end{array}\right)$ & 8616 & 6128 & $\mathrm{~S}_{4} \mathrm{Cu}_{3} \mathrm{~V}$ & 215-eda \\
\hline$\left(\begin{array}{lll}12 & 6 & 24\end{array}\right)$ & $\left(\begin{array}{lll}8 & 3 & 4\end{array}\right)$ & $\begin{array}{lll}6 & 12 & 12\end{array}$ & $\mathrm{Ni}_{2} \mathrm{Mn}_{3} \mathrm{Si}$ & 227-efc \\
\hline$\left(\begin{array}{lll}12 & 6 & 24\end{array}\right)$ & $\begin{array}{lll}6 & 12 & 12\end{array}$ & $\begin{array}{lll}6 & 12 & 12\end{array}$ & $\mathrm{O}_{2} \mathrm{Li} \mathrm{Ti}$ & 227-edc \\
\hline$\left(\begin{array}{lll}12 & 6 & 24\end{array}\right)$ & $\begin{array}{lll}6 & 12 & 12\end{array}$ & $4 \quad 12 \quad 12$ & $\mathrm{O}_{4} \mathrm{Al}_{2} \mathrm{Mg}$ & 227-ecb \\
\hline$\left(\begin{array}{lll}12 & 6 & 24\end{array}\right)$ & $\left(\begin{array}{lll}6 & 12 & 8\end{array}\right)$ & $\left(\begin{array}{lll}6 & 12 & 8\end{array}\right)$ & C Y Co & 131-cfa \\
\hline$\left(\begin{array}{lll}12 & 6 & 24\end{array}\right)$ & $\left(\begin{array}{lll}6 & 12 & 6\end{array}\right)$ & $\left(\begin{array}{lll}6 & 6 & 12\end{array}\right)$ & $\mathrm{Ni} \mathrm{Sb} \mathrm{S}$ & 198-аaа \\
\hline$\left(\begin{array}{lll}12 & 6 & 2\end{array}\right)$ & $\left(\begin{array}{lll}12 & 6 & 2\end{array}\right)$ & $\left(\begin{array}{lll}8 & 12 & 6\end{array}\right)$ & $\mathrm{Ga} \mathrm{Ge} \mathrm{Li}$ & 186-bba \\
\hline$\left(\begin{array}{lll}12 & 6 & 2\end{array}\right)$ & $\left(\begin{array}{lll}12 & 6 & 2\end{array}\right)$ & $\left(\begin{array}{lll}8 & 12 & 6\end{array}\right)$ & $\mathrm{Be} \mathrm{Si} \mathrm{Zr}$ & 194-cda \\
\hline$\left(\begin{array}{lll}9 & 6 & 8\end{array}\right)$ & $\left(\begin{array}{lll}9 & 6 & 8\end{array}\right)$ & 488 & $\mathrm{Pt}_{4} \mathrm{Ge}_{4} \mathrm{Na}_{3}$ & 217-ccb \\
\hline$\left(\begin{array}{lll}9 & 6 & 8\end{array}\right)$ & 8612 & 488 & $\mathrm{~S}_{4} \mathrm{~V} \mathrm{Tl}_{3}$ & 217-cab \\
\hline$\left(\begin{array}{lll}8 & 12 & 6\end{array}\right)$ & $\left(\begin{array}{lll}8 & 12 & 6\end{array}\right)$ & $\left(\begin{array}{lll}8 & 12 & 6\end{array}\right)$ & $\mathrm{Li} \mathrm{Ba} \mathrm{Si}$ & 187-eda \\
\hline$\left(\begin{array}{lll}8 & 12 & 6\end{array}\right)$ & $\left(\begin{array}{lll}8 & 12 & 6\end{array}\right)$ & $\left(\begin{array}{lll}3 & 8 & 9\end{array}\right)$ & $\mathrm{N} \mathrm{Li} \mathrm{Li}{ }_{2}$ & 191-abc \\
\hline$\left(\begin{array}{lll}8 & 12 & 6\end{array}\right)$ & $\left(\begin{array}{lll}4 & 6 & 14\end{array}\right)$ & $\left(\begin{array}{lll}3 & 8 & 9\end{array}\right)$ & $\mathrm{SnCo}_{3} \mathrm{Sn}_{2}$ & 191-afd \\
\hline$\left(\begin{array}{lll}8 & 12 & 6\end{array}\right)$ & $\left(\begin{array}{lll}4 & 6 & 14\end{array}\right)$ & $\left(\begin{array}{lll}3 & 8 & 9\end{array}\right)$ & $\mathrm{Ca} \mathrm{Cu}_{3} \mathrm{Cu}_{2}$ & $191-a g c$ \\
\hline$\left(\begin{array}{lll}8 & 12 & 4\end{array}\right)$ & $\left(\begin{array}{lll}8 & 12 & 4\end{array}\right)$ & $\left(\begin{array}{lll}8 & 12 & 4\end{array}\right)$ & $\mathrm{La} \mathrm{Pt} \mathrm{Si}$ & 109-аaа \\
\hline $\begin{array}{lll}8 & 6 & 16\end{array}$ & 8616 & 6128 & $\mathrm{~S}_{3} \mathrm{U}_{3} \mathrm{U}$ & 221-dca \\
\hline 8616 & $\begin{array}{lll}6 & 12 & 8\end{array}$ & 6128 & $\mathrm{O}_{3} \mathrm{Ca} \mathrm{Ti}$ & 221-dba \\
\hline 8612 & $\begin{array}{lll}6 & 12 & 8\end{array}$ & 2816 & $\mathrm{Na} \mathrm{O}_{4} \mathrm{Pt}_{3}$ & 223-aec \\
\hline $8 \quad 6 \quad 12$ & $\left(\begin{array}{lll}4 & 9 & 6\end{array}\right)$ & $\left(\begin{array}{lll}4 & 8 & 8\end{array}\right)$ & $\mathrm{Ga} \mathrm{Ni}_{3} \mathrm{Ga}_{3}$ & 230-agf \\
\hline 848 & 848 & $\left(\begin{array}{lll}3 & 2 & 12\end{array}\right)$ & $\mathrm{Ca}_{3} \mathrm{U}_{3} \mathrm{~S}_{4}$ & $220-a b c$ \\
\hline$\left(\begin{array}{lll}6 & 12 & 12\end{array}\right)$ & $\left(\begin{array}{lll}6 & 12 & 12\end{array}\right)$ & $\left(\begin{array}{lll}6 & 12 & 12\end{array}\right)$ & Mo S S & 160-аaа \\
\hline$\left(\begin{array}{lll}6 & 12 & 12\end{array}\right)$ & $\left(\begin{array}{lll}6 & 12 & 12\end{array}\right)$ & $\left(\begin{array}{lll}6 & 8 & 18\end{array}\right)$ & Cd I I & 186-bba \\
\hline$\left(\begin{array}{lll}6 & 12 & 12\end{array}\right)$ & $\left(\begin{array}{lll}6 & 12 & 12\end{array}\right)$ & $\left(\begin{array}{lll}6 & 2 & 18\end{array}\right)$ & K As Sn & 186-bba \\
\hline$\left(\begin{array}{lll}6 & 12 & 8\end{array}\right)$ & $\left(\begin{array}{lll}6 & 12 & 8\end{array}\right)$ & $\left(\begin{array}{lll}4 & 6 & 8\end{array}\right)$ & $\mathrm{Sr} \mathrm{Pb} \mathrm{Pb}$ & 123-ace \\
\hline 6128 & 6128 & $\left(\begin{array}{lll}2 & 8 & 16\end{array}\right)$ & W Ge $\mathrm{Al}_{6}$ & 200-abf \\
\hline 6128 & $\left(\begin{array}{lll}5 & 8 & 1\end{array}\right)$ & $(425)$ & $\mathrm{Si}_{2} \mathrm{Ce}_{3} \mathrm{Ni}_{6}$ & 229-ceh \\
\hline 6128 & $\left(\begin{array}{lll}6 & 1 & 4\end{array}\right)$ & $\left(\begin{array}{lll}4 & 2 & 8\end{array}\right)$ & $\mathrm{Ag}_{2} \mathrm{Ag}_{6} \mathrm{Ca}_{3}$ & 229-che \\
\hline$\left(\begin{array}{lll}6 & 12 & 8\end{array}\right)$ & $\left(\begin{array}{lll}2 & 4 & 10\end{array}\right)$ & 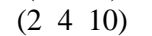 & $\mathrm{U}_{2} \mathrm{U}(\mathrm{U}, \mathrm{Mo})$ & 123 -еас \\
\hline 6126 & $\left(\begin{array}{lll}6 & 2 & 2\end{array}\right)$ & $\left(\begin{array}{lll}3 & 7 & 6\end{array}\right)$ & $\mathrm{C} \mathrm{Mo}_{3} \mathrm{Al}_{2}$ & 213-adc \\
\hline$\left(\begin{array}{lll}6 & 8 & 18\end{array}\right)$ & $\left(\begin{array}{lll}6 & 8 & 18\end{array}\right)$ & $\left(\begin{array}{lll}6 & 8 & 18\end{array}\right)$ & $\mathrm{Ni} \mathrm{Ni} \mathrm{H}$ & $156-a b c$ \\
\hline$\left(\begin{array}{lll}6 & 8 & 4\end{array}\right)$ & $\left(\begin{array}{lll}5 & 6 & 6\end{array}\right)$ & $\left(\begin{array}{lll}2 & 6 & 14\end{array}\right)$ & $\mathrm{Co}_{3} \mathrm{~B}_{2} \mathrm{Ce}$ & 191-gca \\
\hline$\left(\begin{array}{lll}6 & 6 & 12\end{array}\right)$ & $\left(\begin{array}{lll}6 & 6 & 12\end{array}\right)$ & $\left(\begin{array}{lll}6 & 6 & 12\end{array}\right)$ & $\mathrm{Zr} \mathrm{S} \mathrm{O}$ & 198-аaа \\
\hline$\left(\begin{array}{lll}6 & 6 & 12\end{array}\right)$ & $\left(\begin{array}{lll}6 & 6 & 12\end{array}\right)$ & $\left(\begin{array}{lll}6 & 2 & 18\end{array}\right)$ & $\mathrm{Cd} \mathrm{Cl}(\mathrm{OH})$ & 186-bba \\
\hline$\left(\begin{array}{lll}6 & 6 & 8\end{array}\right)$ & $\left(\begin{array}{lll}6 & 6 & 8\end{array}\right)$ & $\left(\begin{array}{lll}2 & 6 & 14\end{array}\right)$ & In $\mathrm{Ni} \mathrm{Ni}$ & 194-cda \\
\hline$\left(\begin{array}{lll}5 & 6 & 6\end{array}\right)$ & $\left(\begin{array}{lll}4 & 2 & 12\end{array}\right)$ & $\left(\begin{array}{lll}2 & 6 & 14\end{array}\right)$ & $\mathrm{Ni}_{2} \mathrm{Al}_{3} \mathrm{Pr}$ & 191-cga \\
\hline$\left(\begin{array}{lll}4 & 12 & 20\end{array}\right)$ & $\left(\begin{array}{lll}4 & 12 & 20\end{array}\right)$ & $\left(\begin{array}{lll}4 & 6 & 8\end{array}\right)$ & $\mathrm{Ti} \mathrm{Al} \mathrm{Al} l_{2}$ & $139-a b d$ \\
\hline$\left(\begin{array}{lll}4 & 6 & 8\end{array}\right)$ & $\left(\begin{array}{lll}4 & 6 & 8\end{array}\right)$ & $\left(\begin{array}{lll}4 & 6 & 8\end{array}\right)$ & $\mathrm{Fe} \mathrm{Ni} \mathrm{N}$ & 123-cba \\
\hline$\left(\begin{array}{lll}4 & 3 & 1\end{array}\right)$ & 428 & $\left(\begin{array}{lll}1 & 12 & 8\end{array}\right)$ & $\mathrm{Sn}_{4} \mathrm{Sn}_{3} \mathrm{Ir}_{3}$ & 229-fde \\
\hline
\end{tabular}


$x=0.31125$ or 0.2976 values of oxygen atoms in $\mathrm{Sb}_{2} \mathrm{O}_{3}$ or $\mathrm{As}_{2} \mathrm{O}_{3}$ are close to $x^{\prime}=0.3125$ of the undistorted (8 34 ) packing.

Covalent A-A bonding: The structure of pyrite $\left(\mathrm{FeS}_{2}\right)$ with $T_{i}=12624$ of $\mathrm{Fe}$ atoms contains $\mathrm{S}-\mathrm{S}$ dumb-bells with covalent bonding between $\mathrm{S}$ atoms. The same applies for the peroxides like $\mathrm{CdO}_{2}$ with $x^{\prime}=0.09$ of the same structure type (identical lattice complexes for $0 \pm x$ or $1 / 2 \pm x^{\prime}$ ). The $x^{\prime} \approx 0.16$ value of $\mathrm{SiO}_{2}$ and $\mathrm{PdF}_{2}$ without $\mathrm{O}-\mathrm{O}$ or $\mathrm{F}-\mathrm{F}$ bonding is close to $x=(-1+\sqrt{5}) / 8$ of the lattice complex with $T_{i}$ values 763 (Table 3). The $\mathrm{O}$ atoms in $\mathrm{CO}_{2}$ with $x \approx 0.12$ contain a $\mathrm{C}$ atom in the center of the dumb-bell (linear $\mathrm{O}=\mathrm{C}=\mathrm{O}$ molecules).

Combinations of packings: The invariant cubic $\mathrm{F}$ and $\mathrm{T}$ lattice complexes [5] with $T_{i}$ values (12 6 24) and (6 12 12) occur in different space groups 225 and 227. The $x=0.245$ value of $\mathrm{Ti}$ atoms in the $\mathrm{Ti}_{2} \mathrm{C}$ structure $\left(\mathrm{CdCl}_{2}\right.$ antistructure type) is close to $x=1 / 4$ of the (12 6 24) packing. The cubic $\mathrm{F}$ and $\mathrm{P}$ (primitive cubic lattice with $T_{i}$ values 6128 ) lattice complexes of space groups 225 and 221 are combined in the ratio $1: 2$ in the invariant $\mathrm{CaF}_{2}$ structure. The combination in the ratios $4: 1$ or $1: 1$ in $\mathrm{Fe}_{4} \mathrm{C}$ or PtS is not possible in an invariant structure. The $x=0.265$ value of $\mathrm{Fe}$ atoms in $\mathrm{Fe}_{4} \mathrm{C}$ is close to $x=1 / 4$ of the undistorted lattice.

Combinations of distorted packings: The $c / a=1.41$ and $c / a^{\prime}=2$ values of undistorted $\mathrm{F}$ and $\mathrm{P}$ complexes in $\mathrm{PtS}$ are different. The $c / a=1.758$ value of $\mathrm{PtS}$ is intermediate. The same applies for the combination of the hcp sphere packing (1262) with $c / a=1.633$ and two primitive hexagonal packings $\mathrm{ph}^{\prime}$ (8 12 6) with $c^{\prime} / a=2$ in SV with $c / a=1.73$ or SFe with $c / a=1.69$. A different complex (2 614$)$ at $c / a=1.155$ is approximated for metal atoms with decreased $c / a=1.548(\mathrm{SNi})$ or $1.525(\mathrm{SCr})$. The $(668)$ packing with $c / a=1.33$ is approximated for $\mathrm{Se}, \mathrm{As}$ or $\mathrm{Sb}$ atoms in $\mathrm{SeNi}(c / a=1.46), \mathrm{AsNi}$ (1.39) or SbNi (1.31). The formation of the (2 614$)$ chain of $\mathrm{Ni}$ atoms with $T_{1}=2$ nearest neighbors in $c$ direction is probably related with attractive $\mathrm{Ni}-\mathrm{Ni}$ interactions.

Combinations of three or more packings: Compounds with three or more Wyckoff positions (Table 4) are frequently related with binary compounds. The three compounds $\mathrm{PtCl}_{6} \mathrm{~K}_{2}, \mathrm{~S}_{4} \mathrm{Cu}_{3}$ As and $\mathrm{S}_{4} \mathrm{Cu}_{3} \mathrm{~V}$ with the (12 6 24), (8 6 16) and (6 12 8) packings of $\mathrm{A}, \mathrm{B}$ and $\mathrm{C}$ atoms for example are related to $\mathrm{CaF}_{2}$ or $\mathrm{Fe}_{4} \mathrm{C}$ with (12 6 24) and (6 12 8) packings in the ratio $1: 2$ or $4: 1$ and to $\mathrm{Cu}_{3} \mathrm{Au}$ or $\mathrm{O}_{3} \mathrm{Re}$ with $(8616)$ and (6 128$)$ packings in the ratio $3: 1$. The $\mathrm{B}$ and $\mathrm{C}$ atoms of $\mathrm{Cu}_{3} \mathrm{Au}$ and $\mathrm{S}_{4} \mathrm{Cu}_{3} \mathrm{As}$ or $\mathrm{O}_{3} \mathrm{Re}$ and $\mathrm{S}_{4} \mathrm{Cu}_{3} \mathrm{~V}$ have the translations $1 / 21 / 20$ or $1 / 200$.

Colloids and micelles: Colloidal particles can crystallize in (12 6 24) (fcc-), (10 4 8) (bct-), (8 12 6) (bcc-), (2 8 4) (sft-) or (2 2 8) (bco-colloids) packings [18]. Binary mixtures of colloidal particles with different sizes were observed in (8 12 6) (3 6 5) $\mathrm{AlB}_{2},\left(\begin{array}{l}6 \\ 6\end{array}\right.$ 
(4 6 14) (3 8 9) $\mathrm{CaCu}_{3} \mathrm{Cu}_{2}$ or (6 12 12) (4 12 12) $\mathrm{Cu}_{2} \mathrm{Mg}$ structures (Table 4) [19]. The $\mathrm{NaZn}_{13}$ and $\mathrm{CaCu}_{5}$ structures are examples of different neighborhoods of B particles. Different packings were also observed for micelles [20] in Wyckoff positions 225-a (12 6 24), 229-a (8 6 12), 223-ac (8 612 and 28 16) or 227-da (6 1212 and 41212 ).

\section{Surfaces of cylinders or spheres}

Some circle packings with high density like 666 or 444 can be related to the ordering of leaves (phyllotaxis) [21,22]. This can be shown, if the packing within the periodic boundary lines [2] is rolled to a cylinder around the stem of the plant. Whorles with $v=6$ leaves for example can be compared with the table of $v=6$ ladies A (Sect. 1). The ordering is periodic within a short section of the stem. The A positions show the directions of leaves. The formation of single spirals $(\nu=1)$ with an angle $\beta \approx 360^{\circ} / \tau^{2} \approx 138^{\circ}(\tau=(1+\sqrt{5}) / 2)$ [22] can be described by a distorted (4 4 4) packing of $n=2$ rhombs with angle $\gamma \approx 99^{\circ}$ and the inclination angle $\alpha$. Other spirals like the $\alpha$-helix $(n=3)$ or a double helix $(v=2)$ with $v n=10$ or 12 base pairs are obtained at variation of $n$ and $\gamma$ :

$$
\begin{aligned}
& \nu \beta=\frac{360(n-\cos \gamma)}{n^{2}-2 n \cos \gamma+1}, \quad \tan \alpha=\frac{\sin \gamma}{n-\cos \gamma}, \quad \text { rise }=\sin \alpha, \\
& n \beta=360 \cos \gamma \quad(\alpha=0), \quad \text { rise }=\sin \gamma .
\end{aligned}
$$

A pairwise spiral is also obtained for $n=2$ rhombs with $\alpha=0^{\circ}$ and different $\beta$ values at varied angles $\gamma$ of the rhombs (Eq. 2). A double helix with $v=2$ leaves at the same height of the stem is observed for the stinging nettle as example. The spiral growth in the 666 or 444 packing is observed for about $80 \%$ of the plants [21,22]. The density of leaves is decreased in the 363 honeycomb or 446 kagomé net on the cylinder surface. $33 \%$ or $25 \%$ of the positions of the hexagonal net (6 6 6) are vacant.

Other structures can be considered as circle packings on the surface of a sphere (Platonic or Archimedean solids) [2]. The highest density of homogeneous solids is obtained for the icosahedron with $T_{i}$ values 551 of the $T_{1}+$ $T_{2}+T_{3}+1=12$ vertices $v$ in alloys or polyoxomolybdates. The density is increased for viruses with $T_{1}=5$ or $T_{1}=6$ values of capsomeres protecting the virus genome. The capsomeres of the tobacco mosaic virus form a single spiral $(v=1)$ with $n=17$ rhombs. The $\beta$ values of the helices in cholesteric liquid crystals increase at increased temperatures [9].

The curved eyes of many insects like flies, bees or dragon-flies contain many facet eyes in a hexagonal net with a honeycomb frame [23]. The muscle of the fly (bombylius major) has a hyperbolic surface with a hexagonal net of bundles of myosin molecules and a kagomé net of actin molecules. 


\section{Conclusion}

All 2D or 3D structures can be characterized by lattice complexes with increased self-coordination numbers of nearest, second and third A-A neighbors $T_{i}, i=1-3$, if the values for more than one parameter $c / a, \cos \gamma$ or $x$ (Tables 1 and 3) are available. The homogeneous $\mathrm{A}_{x} \mathrm{~B}_{y}$ structures are characterized by two lattice complexes for $\mathrm{A}$ and $\mathrm{B}$ positions. The same applies for two directions $\mathrm{A}$ and $\mathrm{B}$ for the ordering of magnetic moments or the ordering of organic molecules [2]. The lattice complexes for organic molecules with more than one parameter are not yet determined. Curved surfaces like the surfaces of cylinders or spheres are analyzed by $T_{i}, i=1-3$ values for phyllotaxis or the ordering of capsomeres of viruses.

Most homogeneous structures with identical $T_{i}$ values of $\mathrm{A}$ and $\mathrm{B}$ can be related with different interactions. Pauling's rule of parsimony is obeyed for the homogeneous structures with identical neighborhood: The number of essentially different kinds of constituents in a crystal tends to be small [24]. The $\mathrm{AB}, \mathrm{AABB}$ or $\mathrm{ABB}$ sequences of the linear row are observed for most homogeneous 2D and 3D structures [2]. Most structures of the 555 or 521 nets are not homogeneous. A structure with $T_{1}=5$ neighbors cannot be divided in equal parts because of the absence of a five-fold symmetry operation. The honeycomb (3 63 ), square (4 4 4) and hexagonal (6 6 6) nets are examples with $T_{1}=3$-, 4- or 6-fold symmetries. $T_{1}=5$-fold symmetry is obtained in the icosahedron (5 5 1). Inhomogeneous 1D structures are essential for DNA sequences, music notes or letters of languages [25].

\section{References}

1. G. O. Brunner, Acta Cryst. A 27 (1971) 388.

2. J. Hauck and K. Mika, Progr. Solid State Chem. 31 (2003) 149.

3. J. Kanamori and Y. Kakehashi, J. Phys. C 7 (1977) 274.

4. J. Hauck and K. Mika, Z. Phys. Chem. 215 (2001) 637.

5. W. Fischer and E. Koch, in: Intern. Tables for Crystallogr., Th. Hahn (Ed.), Vol. A, p. 825. Kluver, Dordrecht (1987).

6. W. Fischer, Z. Kristallogr. 138 (1973) 129.

7. J. M. MacLaren, J. B. Pendry, P. J. Rous, D. K. Saldin, G. A. Somorjai, M. A. Van Hove, and D. D. Vvedensky, Surface Crystallographic Information Service, A Handbook of Surface Structures, D. Reidel, Dordrecht (1988).

8. E. Koch and W. Fischer, in: Intern. Tables for Crystallogr., A. J. C. Wilson and E. Prince (Eds.), Vol. C, p. 738, Kluver, Dordrecht (1999).

9. J. W. Goodby, in: Handbook of Liquid Crystals, D. Demus, J. Goodby, G. W. Gray, H.-W. Spiess, and V. Vill (Eds.), Vol. 2a, p. 3, Wiley-VCH, Weinheim (1998).

10. D. W. M. Hofmann and J. Apostolakis, J. Molec. Struct. 647 (2003) 17.

11. A. I. Kitaigorodski, Organic Chemical Crystallography, Consultants Bureau, New York (1961).

12. A. J. C. Wilson, V. L. Karen, and A. Mighell, in: Intern. Tables for Crystallogr., A. J. C. Wilson and E. Prince (Eds.), Vol. C, p. 889, Kluver, Dordrecht (1999).

13. J. Hauck and K. Mika, Cryst. Res. Technol. 39 (2004) 655.

14. S. Lidin, M. Jacob, and S. Andersson, J. Solid State Chem. 114 (1995) 36. 
15. G. Bergerhoff, M. Berndt, K. Brandenburg, and T. Degen, Acta Cryst. B 55 (1999) 147.

16. E. Parthé, L. Gelato, B. Chabot, M. Penzo, K. Cenzual, and R. Gladyshevskii, TYPIX: Standardized Data and Crystal Chemical Characterization of Inorganic Structure Types, in Gmelin Handbook of Inorganic and Organometallic Chemistry, Vol. 4, Springer, Berlin (1993).

17. P. Villars and L. D. Calvert, Pearson's Handbook of Crystallographic Data for Intermetallic Phases, Vol. 1, American Society for Metals, Metals Park, OH (1986).

18. A. Yethiraj and A. van Blaaderen, Nature 421 (January 2003) 513.

19. S. Yoshimura and S. Hachisu, Progr. Colloid Polym. Sci. 68 (1983) 59.

20. J. M. Seddon, Ber. Bunsenges. Phys. Chem. 100 (1996) 380.

21. I. Adler, D. Barabe, and R. V. Jean, Ann. Botany 80 (1997) 231.

22. P. Ball, The Self-made Tapestry: Pattern Formation in Nature, Oxford University Press, Oxford (1999).

23. J. Burgess, M. Marten, and R. Taylor, Microcosmos, Cambridge Univ. Press, Cambridge (1987).

24. L. Pauling, J. Am. Chem. Soc. 51 (1929) 1010.

25. J. Hauck, D. Henkel, and K. Mika, Physica A 293 (2001) 540. 